\title{
Positive c-ANCA in Henoch-Schonlein purpura: what is the mechanism?
}

\author{
Comment on: Adult-onset Henoch-Schonlein purpura with positive \\ c-ANCA (anti-proteinase 3): case report and review of literature \\ (Rheumatol Int. 2013 Feb; 33(2):493-496)
}

\author{
Ji Eun Kim $\cdot$ Jae Il Shin
}

Received: 3 July 2013/Accepted: 10 July 2013/Published online: 28 July 2013

(C) Springer-Verlag Berlin Heidelberg 2013

Dear Editor,

We read with great interest the recent contribution by Boulis et al. [1]. They reported a case of adult-onset Henoch-Schonlein purpura (HSP) associated with positive cytoplasmic pattern anti-neutrophil cytoplasmic antibodies (c-ANCA), but they did not explicate the possible mechanisms. We would like to suggest a possible pathomechanism of positive c-ANCA in HSP.

We also studied about the prevalence of ANCA (c-ANCA and p-ANCA) in 30 Korean children with HSP and only one of them had weakly positive result of perinuclear pattern ANCA (p-ANCA), which became negative at follow-up [2]. Therefore, we think that c-ANCA or p-ANCA may not be an important serologic marker in children with HSP.

Kallenberg CG described that inflammatory cytokines, such as interleukin (IL)-1 beta and tumor necrosis factor (TNF)-alpha, make priming of neutrophils (membrane expression of proteinase 3 [PR3]) and upregulation of adhesion molecules on their surface as well as on the vascular endothelium [3]. They reported that primed neutrophils adhere to the endothelial cells and released PR3 can be processed and presented by antigen presenting cells (APCs) to T-helper cells [3] They also speculated that as T-regulatory cells (Tregs) cannot inhibit the autoimmune response in Wegener's granulomatosis, autoreactive T cells might undergo repeated stimulation by PR3-pulsed APCs,

J. E. Kim · J. I. Shin $(\square)$

Department of Paediatrics, Severance Children's Hospital,

Yonsei University College of Medicine, Yonsei-Ro 50,

Seodaemun-Ku, C.P.O. Box 8044, Seoul 120-752, Korea

e-mail: shinji@yuhs.ac

J. E. Kim

e-mail: jichunnim@gmail.com and therefore, PR3-stimulated Th cells act on B cells, enhancing the production of ANCA [3].

Because it was shown that TNF-alpha levels are elevated in the acute phase of HSP [4] and regulatory T cells including $\mathrm{CD}(4+) \mathrm{CD}(25+)$ Tregs were significantly lower in patients with HSP than those of controls $(P<0.05)$ [5], there is the possibility that TNF-alpha and defective Tregs may play important role in priming of neutrophils and elevation of c-ANCA in some patients with HSP.

However, because the positive results of ANCA are very rare in patients with HSP, further studies are necessary to elucidate the role of neutrophil priming and ANCA in the pathogenesis of HSP.

\section{References}

1. Boulis E, Majithia V, McMurray R (2013) Adult-onset HenochSchonlein purpura with positive c-ANCA (anti-proteinase 3): case report and review of literature. Rheumatol Int 33(2):493-496

2. Choi JN, Shin JI, Lee JS, Kim HS (2008) Antineutrophil cytoplasmic antibody in Korean children with Henoch-Schonlein purpura. Korean Soc Pediatr Nephrol 12(2):164-169

3. Kallenberg CG (2010) Pathophysiology of ANCA-associated small vessel vasculitis. Curr Rheumatol Rep 12(6):399-405

4. Ha TS (2005) The role of tumor necrosis factor-alpha in HenochSchonlein purpura. Pediatr Nephrol 20(2):149-153

5. Yang J, Li CR, Zu Y, Wang GB, Li YB (2006) Role of regulatory $\mathrm{T}$ cells in pathogenesis of Henoch-Schonlein purpura in children. Zhonghua Er Ke Za Zhi 44(6):411-414 